\title{
XENES, HISTORIA E LINGUA: ESTRUTURA XENÉTICA DA POBOACIÓN GALEGA
}

\author{
Antonio Salas Ellacuriaga e Ángel Carracedo Álvarez.
}

Universidade de Santiago de Compostela

\section{XenEs, Historia E LINGUA}

¿Que é o que nos poden contar os nosos xenes (o noso ADN) da nosa propia historia? A tentación para un científico é procurar explicar a historia desde o punto de vista da xenética, o cal é un erro porque a historia dun pobo non é a historia dos seus xenes, senón un proceso cultural moito máis complexo.

Os pobos van construíndose a si mesmos nun proceso que non ten fin e os seus sinais de identidade poden renovarse, alterarse ou desaparecer. O que nun momento pode resultar alleo, invasor, pódese converter máis adiante no máximo sinal de identidade, como acontece coa nosa propia lingua, aprendida dos conquistadores romanos.

É necesario aclarar que os saberes e as aprendizaxes non quedan rexistrados no código xenético (e, polo tanto, non se herdan xeneticamente). Non obstante, en ocasións existe certo paralelismo entre a herdanza da cultural e a herdanza dos xenes, simplemente porque a miúdo os movementos culturais van acompañados de movementos demográficos, e son precisamente estes movementos demográficos os que deixan a pegada nos xenes.

Polo tanto, é indubidable que os xenes poden contarnos cousas dos nosos antecesores, e o estudo do noso ADN pode ser una ferramenta máis para os historiadores que, xunto cos datos derivados doutras ciencias tales como a arqueoloxía ou a lingüística (en especial a toponimia), lles permite reconstruír mellor o noso pasado. Particularmente o estudo do ADN é esencial para entender os momentos da historia en que os datos arqueolóxicos non existen ou son limitados.

R. Álvarez, F. Dubert, X. Sousa (eds.): Lingua e Territorio Santiago de Compostela: ILG/CCG, 2006, 55-66 ISBN 84-96530-20-5 


\section{EvOLUCIÓN LINGÜÍSTICA E XENÉTICA: ANTECEDENTES}

¿Por que cabe esperar un parecido entre a evolución lingüística e a evolución xenética? Tal e como xa anticipamos, existen importantes analoxías entre ambos os dous tipos de evolución. Os cambios lingüísticos, igual que no xenoma, xorden en individuos concretos e transmítense pouco a pouco ao resto da poboación, do mesmo xeito que os cambios no xenoma (chamados tecnicamente mutacións). Isto a miúdo precisa do paso de moitas xeracións para que o cambio se estabilice. Cabe esperar que os cambios nas linguas se transmitan moitísimo máis rápido e sexan máis fluídos que os cambios no xenoma (ver comentarios máis abaixo). A diferenza dos cambios lingüísticos, as mutacións nos xenes son máis ou menos constantes no tempo, polo tanto, os xenes actúan en certo modo como unha especie de reloxo molecular; por suposto, un reloxo coa súa imprecisión intrínseca (tamén cuantificable). Unha vez calibrado o reloxo, tan só necesitamos cuantificar o número de diferenzas acumuladas no tempo e así cuantificar canto tempo puido transcorrer despois dun evento demográfico concreto.

Sábese dende hai uns poucos anos que existe un paralelismo entre linguas e xenes, sobre todo cando se examina este paralelismo a unha escala mundial. Sabemos que as grandes familias lingüísticas datan dende hai 6.000-25.000 anos; algunha familia podería ser máis antiga (as linguas australianas e indopacíficas poderían ter sobre 40.000 anos). Doutras temos máis incerteza, porque a datación é moito máis complexa (por exemplo as linguas koisánidas). Con moito, a familia lingüística máis coñecida é a indoeuropea, se ben a discusión sobre as súas orixes é tema de intenso e prolongado debate entre lingüistas. Sábese que a correlación entre linguas e xenes non é perfecta, porque as grandes conquistas poden implicar substitucións rápidas por linguas non emparentadas. Porén, estas substitucións non son xeralmente tan dramáticas como para erosionar completamente esta correlación, e de feito hoxe sábese que esta correlación é positiva e estatisticamente significativa.

Grazas ao estudo do noso ADN sabemos hoxe que o home moderno no ten máis de 150.000 anos e que conviviu sen chegar a se mesturar co home de Neandertal. Traballos do noso grupo puideron explicar, por exemplo, como foi a expansión das linguas bantú na África subsahariana (Salas et al. 2002, Plaza et al. 2004, Beleza et al. 2005), un dos 
máis grandes movementos demográficos da historia da humanidade, e reconstruír así a historia de África, onde os datos arqueolóxicos son case inexistentes e os datos lingüísticos pouco auxiliadores.

A substitución das linguas non é o único elemento perturbador da correlación entre linguas e xenes. A miúdo os xenes tamén son substituídos na poboación por mor das grandes conquistas humanas ou movementos poboacionais. O caso máis evidente atopámolo nos países onde conviven grupos poboacionais con ancestralidades recentes moi diversas (países de América Central, Caribe, Estados Unidos, etc.), como froito de eventos demográficos pouco afortunados (conquista das Américas polos grandes imperios europeos, tráfico de escravos, etc.). A xenética xoga un papel de enorme importancia nestes contextos, e a miúdo obsérvase unha gran correlación entre os datos xenéticos e a documentación histórica, tal e como puidemos constatar en traballos do noso grupo (Salas et al. 2002, 2004, 2005).

Sen dúbida, é máis doado co ADN achegar datos á historia dun continente que a de pobos máis pequenos. Porén, a nivel máis local, sábese que nas poucas rexións estudadas ata o momento con certo detalle, as linguas e os xenes tamén mostraron correlacións altas (Barrantes et al. 1990, Cappello et al. 1996). Ademais, con frecuencia, o mosaico xenético-lingüístico observado mostra claramente os efectos de numerosas expansións coñecidas na historia, así como as súas superposicións e interaccións.

A evolución das linguas é un tema de maior interese para coñecer a historia dun pobo, xa que é este o elemento cultural que lle é máis propio. A xenética pode, sen lugar a dúbidas, axudar ao entendemento de determinados patróns lingüísticos.

Cómpre facer tamén un apuntamento relacionado coa variabilidade xenética humana: os seres humanos temos un ADN moi semellante, cun $99,9 \%$ de identidade, no que, ademais, a maior parte da variabilidade acontece dentro das poboacións (nada menos que un 96\%). Quere isto dicir que, se consideramos dous individuos da mesma poboación, estes son só un 4\% máis iguais xeneticamente que dous individuos collidos ao chou de dúas poboacións distintas. Estas porcentaxes diminúen aínda máis cando as poboacións son máis próximas xeneticamente (isto quere dicir en moitas ocasións, próximas xeograficamente). De aquí se deduce que se queremos atopar diferenzas significativas entre dúas 
poboacións ou dentro de poboacións, a) será tanto máis doado canto máis distantes xeneticamente sexan, e b) se as poboacións son moi próximas, haberá que aumentar moito o numero de rexións xenómicas que hai que estudar para atopar un número significativo delas que permitan diferenciar esas poboacións. Se o que queremos é atopar patróns xenéticos significativos a nivel rexional (como pode ser dentro da poboación galega), teremos o problema de que necesitaremos aumentar moito a resolución do noso estudo, xa que a poboación galega (o mesmo que a maior parte das poboacións europeas) é moi homoxénea. Isto a miúdo, dende o punto de vista técnico (en xenética) ten certas complicacións que escapan ao contido do presente capítulo.

\section{OS XENES (LIÑAXES) DA POBOACIÓN FEMININA E DA POBOACIÓN} MASCULINA

Cando falamos de liñaxes xenéticas, referímonos a elementos (partes do xenoma humano) perfectamente diferenciables (para non entrar en detalles técnicos, imaxinemos e asumamos aquí que os xenetistas temos os métodos de laboratorio axeitados para ler o ADN) que están máis ou menos emparentados entre eles, e para os cales a miúdo somos capaces de situar xeograficamente de acordo coa súa orixe poboacionalxeográfica (isto forma parte dunha subdisciplina da xenética coñecida como filoxeografía). Un paralelismo podería ser o estudo das raíces lingüísticas dun texto; así, parte do traballo dun lingüista é examinar un texto na procura dos elementos latinos, prelatinos (amorodo, cama, camiño, etc.), xermánicos (Elvira, Fernando, etc.), árabes (aldea, ata, etc.), e outros. Polo tanto, cando as poboacións se moven, os individuos son portadores das súas linguaxes, pero tamén das liñaxes xenéticas que portan. Un pode examinar neses xenes e liñaxes a evolución que sobre eles tivo lugar, igual que un lingüista examina un texto e o proceso evolutivo que puido acontecer sobre os seus elementos constituíntes.

Os primeiros estudos xenéticos sobre a teoría de migración a nivel microrexional foron realizados fundamentalmente polo prestixioso antropólogo Luigi Luca Cavalli-Sforza (xunto con outros investigadores das universidades de Parma e de Pavía). En xeral estes estudos permitiron verificar que a maior parte dos matrimonios teñen lugar entre 
persoas da mesma vila e que a distancia xenética (como unha medida que cuantifica as diferenzas xenéticas entre poboacións) medra regularmente co aumento da distancia xeográfica entre vilas (illamento debido á distancia). Os cónxuxes a miúdo proceden de lugares moi próximos entre si, segundo unha lei estatística que se pode xeneralizar a vilas de todo o mundo. A muller ou o home proceden da mesma vila e, con menor probabilidade, dunha próxima; o número de persoas da mesma xeración que sae dunha vila acostuma ser o mesmo para todas as vilas.

Porén, desde un punto de vista xenético, habería que agardar ao nacemento dos polimorfismos do chamado ADN mitocondrial (ADNmt) e do cromosoma Y para poder abordar as características concretas dos micromovementos migracionais. Esta é unha particularidade moi especial do xenoma que é necesario aclarar.

A maior parte do noso ADN herdámolo dos nosos pais a partes proporcionais (tecnicamente chamado ADN autosómico localizado no núcleo celular, e que forma os cromosomas autosómicos). Iso é o motivo de por que nos parecemos a eles e aos nosos parentes máis próximos (cos que compartimos máis xenes). Existen non obstante dúas excepcións do ADN máis común. Por un lado está o ADNmt, este é un ADN que é transmitido de nais a fillos (varóns e mulleres), pero só as fillas transmitirán ese ADN aos descendentes. Por outro lado, temos o cromosoma Y, este é un cromosoma sexual, que define neste caso o sexo masculino, polo tanto, é herdado única e exclusivamente do pai home aos fillos homes. É aquí que temos unha característica moi especial e apaixonante do xenoma humano: por unha banda temos un tipo de ADN que rexistra a evolución das liñaxes femininas, mentres que o outro ADN rexistra a evolución das liñaxes masculinas. Polo tanto, se nos movementos demográficos existe distinción entre os movementos de poboación dos homes e as mulleres, cabe a posibilidade de que estes movementos deixen pegada de maneira diferencial nos xenes do ADNmt e o cromosoma Y.

\section{AS LIÑAXES NA POBOACIÓN GALEGA}

En aparencia as variantes do cromosoma Y (aquelas que se herdan por vía exclusivamente paterna) están máis agrupadas xeograficamente 
que as mitocondriais (as que se herdan por vía materna) (Brión et al. 2003 , 2004). Isto significa que para poboacións europeas apenas existe variación mitocondrial, mentres que o cromosoma Y mostra gradientes máis acentuados. Isto explicaríase dunha forma sinxela de considerarmos que a migración do home foi máis limitada cá da muller ao longo da historia.

Esta observación podería parecer contraditoria ao que comunmente se coñece; como di Mark Stoneking (1998: 219), da Universidade de Pensilvania, «a visión que se ten das migracións ao longo da historia é fundamentalmente masculina-dominante; non hai máis que pensar en Marco Polo, Alexandre Magno, Genghis Khan ou Atila (o rei dos hunos). Non obstante, baseándonos en observacións antropolóxicas, sábese que aínda hoxe existen moitas culturas onde a muller se move máis có home xa que esta é a que muda de sitio cando contrae matrimonio e as terras son herdadas polo fillo home (patrilocalidade: tendencia a que a esposa se mude ao lugar natal do home)».

Moi recentemente propuxémonos estudar a poboación galega cun maior nivel de resolución a como o fixeramos con anterioridade. Para iso realizamos mostraxes en distintas rexións de Galicia (52 vilas) con dous obxectivos fundamentais: (a) a análise da poboación galega no contexto das poboacións ibéricas e (b) o estudo intrínseco da poboación galega e a súa estrutura microxeográfica.

Este estudo é demasiado recente como para mostrar resultados e conclusións finais, pero si é interesante amosar unha idea xeral. Para esta análise estudouse o ADNmt e o cromosoma Y. Polo tanto, estamos en condicións de ver o comportamento xenético poboacional destes dous integrantes da poboación: as mulleres e os homes.

De forma resumida poderíanse propor dous modelos poboacionais (cando se fala a esta escala xeográfica) para explicar a microdifusión poboacional:

a) Os movementos poboacionais a pequena escala (estamos a falar de poucos quilómetros) son dabondo importantes como para que nun tempo razoablemente curto se produza unha bomoxeneización xenética da poboación.

b) As poboacións permanecen relativamente estáticas, de forma que os individuos tenden a nacer, medrar, procrear e morrer nos seus lugares de orixe. 

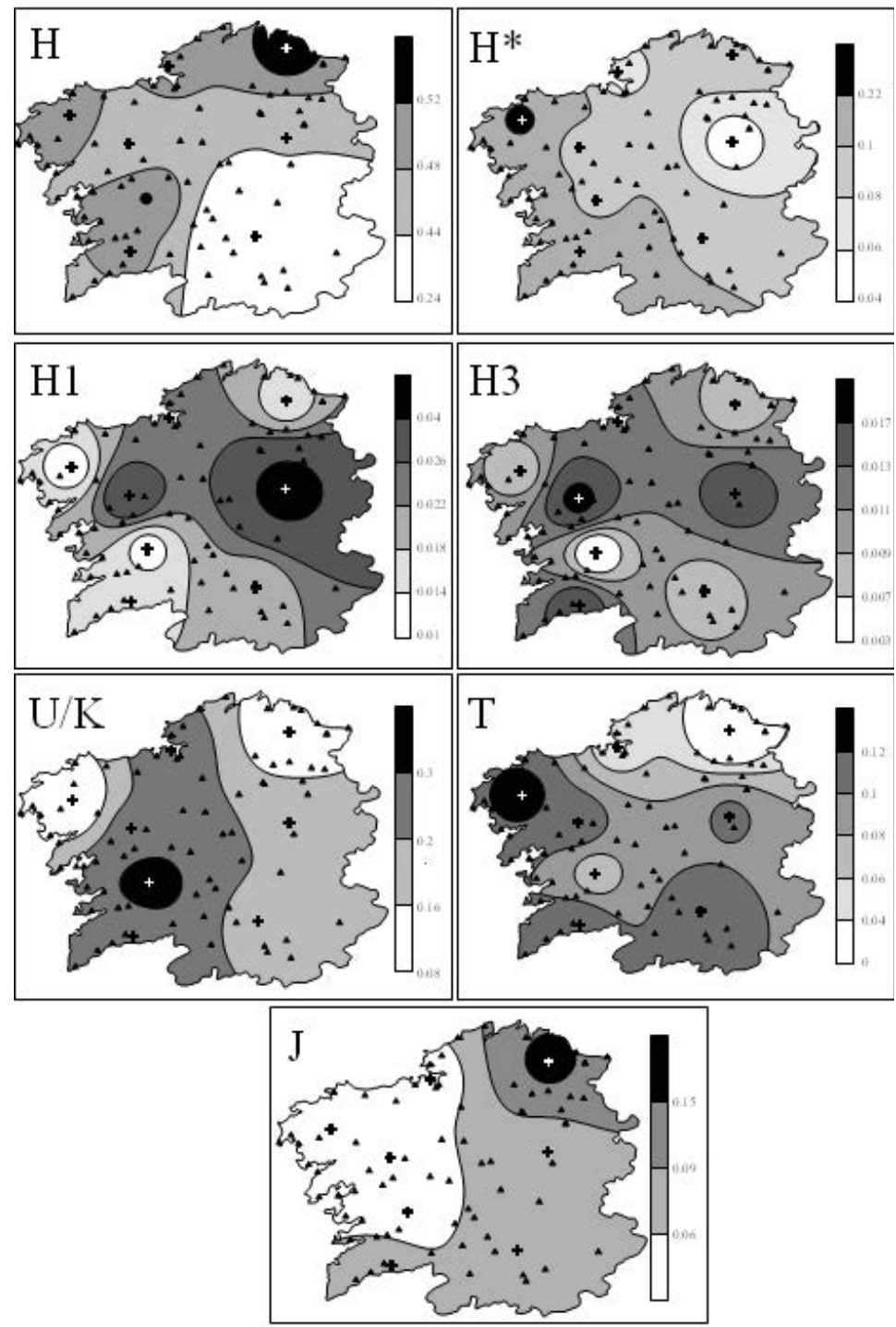

Figura 1. Representación espacial das liñaxes mitocondriais en Galicia; as liñaxes chámanse tecnicamente haplogrupos, xeralmente referenciados cun código de letras acompañadas en ocasións por números (por exemplo, o primeiro mapa da esquina superior esquerda fai referencia ao haplogrupo $H$ ). As liñas que separan áreas non deben considerarse como barreiras xenéticas, senón máis ben 
Estes dous modelos mostran dúas posibilidades demasiado extremas, pero que serven para centrar o problema. Os resultados preliminares obtidos ata o momento revelan que a poboación galega amosa signos de estruturación poboacional a nivel mitocondrial (poboación feminina). Estas diferenzas entre comarcas galegas non se perciben no cromosoma $\mathrm{Y}$, polo que se pode concluír de maneira moi xeral que o modelo a pode ser certo para a poboación de homes, mentres que o modelo $b$ se axustaría máis á poboación feminina.

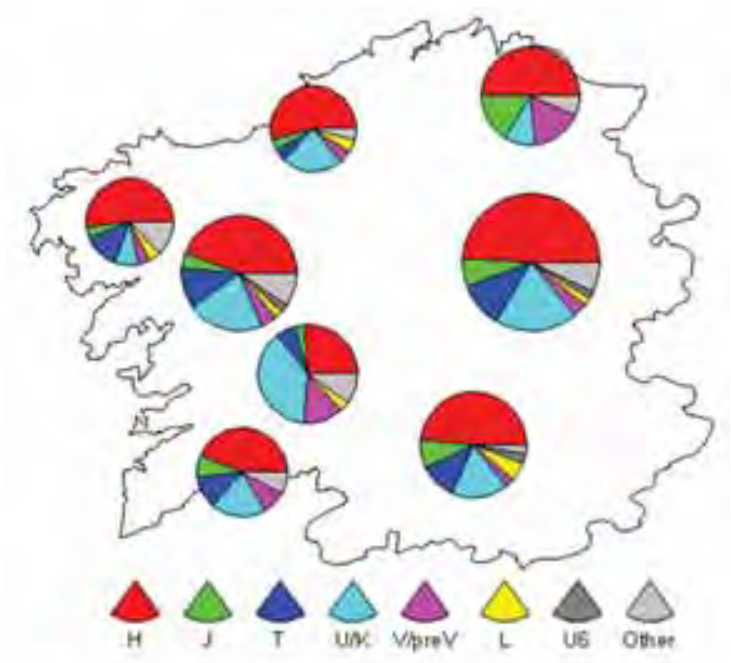

Figura 2. Frecuencia das liñaxes mitocondriais nas distintas comarcas galegas. O tamaño do diagrama de sectores é proporcional ao tamaño da mostra.

Polo tanto, nos datos que imos coñecendo da análise dos nosos xenes aparecen cousas que non entendemos ben. Aparentemente hai máis diferenzas entre comarcas entre xenes que se herdan por vía materna que por vía paterna. Isto non parece que aconteza noutras poboacións e podería ser explicado por unha maior mobilidade dos homes que das mulleres, o que podería ser unha hipótese que apoiase a existencia

como marcas de referencia para valores de frecuencia tal e como se indican na lenda á dereita de cada mapa. É importante destacar que estas distribucións están sometidas a erros de mostraxe, e polo tanto, estes mapas están suxeitos a modificacións baseadas no estudo de mostras independentes e de maior tamaño. 
histórica do matriarcado de que falaba Estrabón, o xeógrafo grego, e que non goza da opinión favorable da maioría dos historiadores, pero sen dúbida pode haber outras causas históricas ou culturais, e mesmo xenéticas, que o expliquen.

A figura 1 é unha representación espacial das frecuencias de determinadas liñaxes mitocondriais na poboación galega (referidas por una letra que representa o que no argot dos xenetistas se coñece como haplogroup). A figura 2 é unha representación das frecuencias desas liñaxes nas distintas comarcas galegas.

Aínda é cedo para medir o alcance destes resultados, pero a aproximación xenética a esta problemática pode ser de grande interese para entender un determinado comportamento social (Salas et al. 1998, 2000).

\section{OUTROS ASPECTOS XERAIS RELACIONADOS CO ADN DOS GALEGOS}

Polo estudo do noso ADN podemos saber por exemplo que as primeiras migracións neolíticas á nosa terra foron máis serodias que noutros lugares da península, o que concorda con datos históricos e coa nosa posición xeográfica.

Sabemos tamén que dentro de Galicia as diferenzas culturais e lingüísticas das distintas comarcas non se reflicten nos nosos xenes na escala que hoxe podemos analizar, froito dunha gran mestura e mobilidade histórica dunhas a outras zonas da nosa terra e isto inclúe tamén o Norte do Portugal (coa excepción apenas perceptible da comarca de Bragança). Ambas as dúas poboacións, Galicia e Norte de Portugal, son, posiblemente, as mellor estudadas a nivel mundial, e esta similitude entre comarcas, que pode ser frustrante para os investigadores da historia ou da lingüística, fai da nosa terra unha das poboacións máis interesantes do mundo para atopar xenes responsables de enfermidades comúns e da resposta a fármacos, pois os resultados da busca destes xenes pode verse alterada en poboacións que teñen diferenzas entre distintas áreas xeográficas ou grupos culturais.

Con todo, o noso relativo illamento histórico e o feito de termos historicamente, polo menos nos últimos dous mil anos, moita máis emigración que inmigración fan que moitas enfermidades xenéticas 
ou cun compoñente xenético, como é o caso do cancro de mama ou colon, mostren en Galicia mutacións causantes de enfermidade practicamente exclusivas da nosa terra e polo tanto, tamén presentes na poboación emigrante galega.

6. LiÑAXES GALEGAS HERDADAS DE POBOS NORTEAFRICANOS E SUBSAHARIANOS

As poboacións europeas son bastante homoxéneas en canto á súa composición mitocondrial e do cromosoma Y, como querendo reflectir a orixe común de todas elas a partir dun substrato común proveniente de Oriente Medio e do oeste asiático. Como xa se anticipou, en Galicia as liñaxes mitocondriais e as do cromosoma Y non escapan a este patrón xeral, polo que é difícil que se poida chegar a un nivel de resolución alto en canto á definición das súas distintas liñaxes e á súa localización xeográfica nalgún lugar de Europa. Existen, non obstante, liñaxes non europeas que si son doadamente detectables. Tal é o caso dalgunha liñaxe que caracteriza as poboacións norteafricanas e subsaharianas. Isto énos útil por exemplo para cuantificar o impacto da poboación árabe que sobre o 710 chegou por primeira vez a Galicia.

Como resultado dos nosos estudos, detectamos pequenas achegas de liñaxes norteafricanas na poboación 'autóctona' galega, o que reflicte que o impacto demográfico destes pobos en Galicia, se ben escaso, foi significativo.

Máis difícil de explicar é o escaso, pero tamén existente, impacto dunha pequena proporción de liñaxes subsaharianas. Por suposto non se pode desbotar a posible introdución destas liñaxes en épocas recentes, se ben nas nosas mostraxes procuramos eliminar o efecto deste tipo de artefactos.

Aínda que estas achegas africanas se poidan situar nun contexto histórico recente, non se pode descartar unha orixe máis ancestral. Os datos que existen aínda son escasos, e as datacións non son aínda posibles.

Tamén se pode dicir que o impacto das poboacións norteafricanas na poboación galega é probablemente máis importante no cromosoma 
Y que no ADNmt. Isto parece que podería encaixar coa documentación histórica segundo a cal a contribución demográfica dos homes sería maior como resultado dunha achega máis importante dos homes que das mulleres durante a invasión árabe.

\section{COMENTARIOS FINAIS}

¿Pode a xenética axudar aos historiadores e aos lingüistas galegos? Aínda é cedo para poder axudar a entender o que puido acontecer nos xenes dos galegos así como para valorar o seu potencial real na reconstrución da historia da Galicia e os patróns lingüísticos. Pero si que se pode anticipar que existen certas preguntas que poderían atopar unha resposta nos xenes (cando se estuden estes coa resolución adecuada); por exemplo, (a) movementos diferenciais entre as poboacións femininas e masculinas na Galicia, o que podería axudar a resolver un tema de debate clásico nas discusións entre historiadores e lingüistas, isto é, o matriarcado (ou matrilocalidade) na poboación galega, (b), unha maior resolución relacionada coas achegas demográficas doutras poboacións ibéricas, europeas, norteafricanas é subsaharianas, así como a datación destes eventos demográficos, e (c) correlacións entre a distribución da variabilidade xenética e as principais variantes lingüísticas dentro da Galicia, así como doutros elementos culturais (por exemplo etnográficos) da poboación galega.

Moitos lectores estarán interesados na pregunta ¿como é o ADN dos galegos? Como xenetistas estamos obrigados a responder: moi parecido ao ADN dos non galegos, sobre todo ao daqueles pobos que temos ao redor. O que máis se parece ao ADN dos galegos é, por suposto, o dos portugueses do norte (non están suficientemente estudados os dos asturianos e leoneses), como o que máis se parece ao ADN dos vascos é o das poboacións que teñen ao redor. Pero nese moi parecido está implícito que aínda que non temos un ADN galego, como ningún pobo o ten, si que presenta sinais de identidade como lle ocorre a outros pobos que se foron definindo froito do seu illamento (maior ou menor) por razóns xeográficas, históricas ou culturais.

Deixemos isto como parangón coa reflexión de que o ADN só non pode explicar a nosa historia, pero pode achegar datos de interese para 
os historiadores, que complementados e entendidos de forma integrada cos doutras disciplinas como a arqueoloxía, a paleoantropoloxía e a lingüística, farán que pouco a pouco entendamos mellor o noso pasado. 